\title{
Invited Discussion on: Rippling Following Breast Augmentation or Reconstruction: Aetiology, Emerging Treatment Options and a Novel Classification of Severity
}

\author{
Kamran Khoobehi ${ }^{1}$
}

Received: 26 March 2019/Accepted: 16 April 2019 /Published online: 28 May 2019

(C) Springer Science+Business Media, LLC, part of Springer Nature and International Society of Aesthetic Plastic Surgery 2019

Level of Evidence $V$ This journal requires that authors assign a level of evidence to each article. For a full description of these Evidence-Based Medicine ratings, please refer to the Table of Contents or the online Instructions to Authors www.springer.com/00266.

The authors should be commended for helping improve the issue of implant rippling. This article addresses two different issues that revolve around rippling. One is the accurate description and classification of rippling and its presentation in the breast after implant surgery. The other is treatment plans for the rippling and emerging options. This classification can be used to plan for treatment based on the severity. Similar to capsular contractures grading scale, we can share our scientific findings in a more helpful manner.

Part of plastic surgery that helps us advance as a field is critically analyzing our techniques and ways to improve them. The first step toward improvement is being able to describe the problem. The patient questionnaire database, BREAST-Q, asks about the expectations of the patient's breast augmentation or reconstruction based on the visibility and palpability of the implant rippling (up to 1 year out). This database is limited due to its follow-up beyond one year and the specificity of its questions. BREAST-Q does not distinguish the differences between positional rippling and rippling in the upright position [1-3]. With the grades of rippling presented in this article, the rippling associated with breast implants can be more accurately

This comment refers to the article available at https://doi.org/10.1007/ s00266-018-1117-y.

\footnotetext{
Kamran Khoobehi

khoobehi@aol.com

Louisiana State University, New Orleans, LA, USA
}

described. With most grading scales, the purpose is to help communicate between physicians as well as help with management. Therefore, grading rippling can help by more accurately treating and/or preventing rippling. Part of the difficulty with helping develop guidelines for treatment lies in the fact that the rippling is likely underreported. Rippling may not be present for several years after breast augmentation, and most studies stop after a few years of follow-up or they may not analyze rippling critically all together. Also making it difficult is the ambiguous wording to describe this condition. Many articles mention rippling and/or palpability as a result of implant breast surgery; however, there is a no attempt to categorize the rippling for therapeutic management [1-11]. Rippling is often poorly described or quantified as well as interchangeable with palpability in some papers [8, 9]. The authors did a good job in grading 1 with palpable only, grade 2 with positional rippling and grade 3 with visible rippling with the patient upright. The grade $1 \mathrm{a}$ and $1 \mathrm{~b}$ seems to describe the most common areas; however, if this is the case, other areas of rippling should be included in the scale (superior, inferior pole). This seems to apply to the breast reconstruction and prepectoral breast augmentation as superior pole rippling is common with thinner chest walls $[10,11]$.

Although the article does a nice job in painting the general ideas of what can cause rippling and possible ways to manage it, the power of this article lies in the language we can now use when describing rippling. The classification can now lead to improved communication on complications and ways to correct or prevent rippling. For example, for grade 1 rippling, we may suggest fat transfer alone could be acceptable. For grade 2, it may be recommended to increase implant size with fat transfer, ADM or pocket tightening. For grade 3, changing implant size, adding ADM with fat and tightening the pocket may be 
recommended. With a grading scale, it may be possible to specifically address how to help predict which patients may develop each of the various grades of rippling. Our next step as a community is to try to predict the patients who are at risk and perform preventive measures, such as fat transfer and/or ADM at the time of the implant placement. As this paper mentions, some rippling is from the impression of the implant surface to the overlying tissues, enlargement of the pocket which creates laxity and pulling of the overlying tissues, implant shape-over- or underfilled causing more folds in the shell. Corrections and prevention include increasing tissue coverage with fat, autologous tissue and/or ADM; reinforcing the pocket with ADM to create a snug fit around the implant; changing the implant texture to smooth to allow for less noticeable rippling; and/or increasing the fill of the implants. As we are learning to treat and hopefully prevent rippling, this helps us better guide our patients in choosing the best initial surgery. Longer-term studies, noting specifically when the rippling presents, may help educate the patients and temper their expectations on future rippling. This would be similar to informing patients with very stretch skin that another breast lift will be likely in the future. If they could not accept rippling, then maybe breast augmentation would not be ideal for them. This article is a great step forward in breast rippling management.

\section{Compliance with Ethical Standards}

Conflict of interest The authors declare that they have no conflicts of interest to disclose. The authors have no financial interest to declare in relation to the content of this Discussion or of the associated article.

Ethical Approval This article does not contain any studies with human participants or animals performed by any of the authors.

Informed Consent For this type of study informed consent is not required.

\section{References}

1. Macadam SA, Ho AL, Lennox PA, Pusic AL (2013) Patientreported satisfaction and health-related quality of life following breast reconstruction: a comparison of shaped cohesive gel and round cohesive gel implant recipients. Plast Reconstr Surg 131(3):431-441

2. Mundy LR, Homa K, Klassen AF et al (2017) Normative data for interpreting the BREAST-Q: augmentation. Plast Reconstr Surg 139(4):846-853

3. Memorial Sloan Kettering Cancer Center. BREAST-Q Version 2.0@ A Guide for Researchers and Clinicians USER'S GUIDE VERSION 2.0 November 2017.

4. Codner MA, Mejia JD, Locke MB, Mahoney A, Thiels C, Nahai FR, Hester TR, Nahai F (2011) A 15-year experience with primary breast augmentation. Plast Reconstr Surg 127(3): $1300-1310$

5. Katzel EB, Bucky LP (2017) Fat grafting to the breast: clinical applications and outcomes for reconstructive surgery. Plast Reconstr Surg 140 (5S Advances in Breast Reconstruction): 69S$76 \mathrm{~S}$

6. Duncan DI (2001) Correction of implant rippling using allograft dermis. Aesthet Surg J 21:81-84

7. Baker BG, Irri R, MacCallum V, Chattopadhyay R, Murphy J, Harvey JR (2018) A prospective comparison of short-term outcomes of subpectoral and prepectoral strattice-based immediate breast reconstruction. Plast Reconstr Surg 141(5):1077-1084

8. Adams WP (2008) The process of breast augmentation: four sequential steps for optimizing outcomes for patients. Plast Reconstr Surg 122(6):1892-1900

9. Spear SL, Sinkin JC, Al-Attar A (2013) Porcine acellular dermal matrix (strattice) in primary and revision cosmetic breast surgery. Plast Reconstr Surg 131(5):1140-1148

10. Spear SL, Seruya M, Clemens MW, Teitelbaum S, Nahabedian MY (2011) Acellular dermal matrix for the treatment and prevention of implant-associated breast deformities. Plast Reconstr Surg 127(3):1047-1058

11. Slavin SA, Lin SJ (2012) The use of acellular dermal matrices in revisional breast reconstruction. Plast Reconstr Surg 130(5 Suppl 2):70S-85S

Publisher's Note Springer Nature remains neutral with regard to jurisdictional claims in published maps and institutional affiliations. 